\section{DENTAL PHOBIC PATIENTS SHOULD BE IDENTIFIED AND TREATED IN CHILDHOOD}

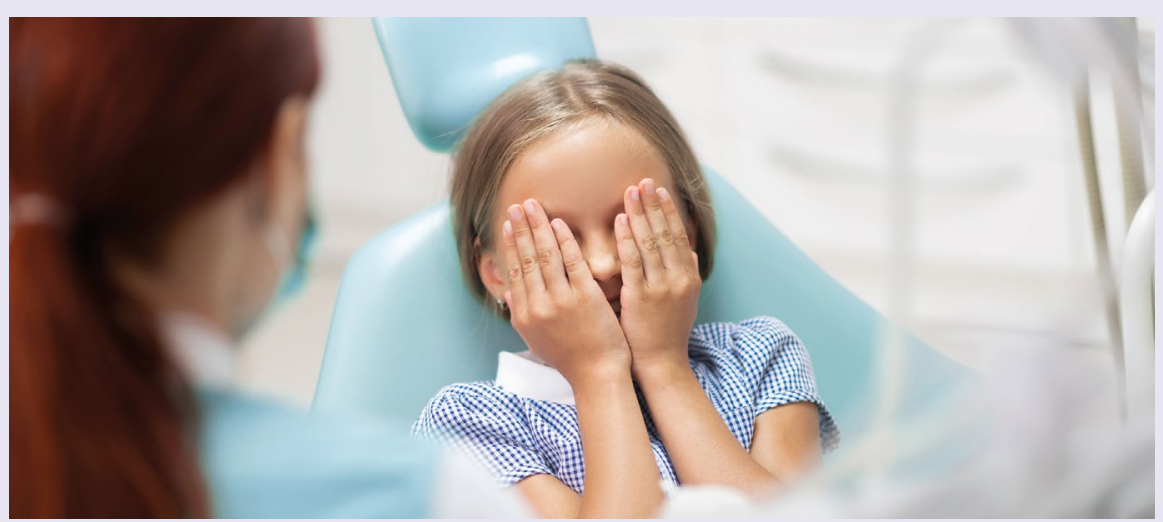

Treating the fear of dental care in childhood is effective and leads to more regular dental examinations later in life, according to a study by the University of Oulu, Finland. ${ }^{1}$

Approximately one in two adults say that they are at least somewhat afraid of dental care, and one in ten says that they are very afraid. One manifestation of dental fear is the avoidance of treatment, which can lead to a vicious circle of deteriorating oral health and pain treatment.

The study followed patients treated at the Clinic for Fearful Dental Patients (CFDP) of the City of Oulu. At the clinic, patients receive help with their dental fear alongside dental treatment as part of comprehensive treatment. The operating model is quite unique in Finland, when the focus is both in dealing with dental fear and simultaneously giving necessary care.

The study investigated the long-term effects of the fear treatment period, ie whether patients visited their own clinics for examinations after the end of treatment in the CFDP; whether they did not visit dental care at all or how often they had to go to primary health care for emergency treatment. The ten-year follow-up included a total of 152 patients.

Head researcher, dental specialist Taina Kankaala said: 'The low-threshold treatment of dental fear in primary health care in conjunction with the dental care of the patient has only been studied to a limited extent. A study on long-term effects has not been published before'.

According to the study, a childhood care period (between the ages of 2-10) at the dental fear clinic was associated with a higher number of dental examinations later on compared to treatment at older age.

Dr Kankaala said: 'It was also surprising how well those who were successfully treated at the fear clinic coped with dental care in primary health care later on. On the other hand, it was as expected that if the treatment was unsuccessful for one reason or another, dental care visits would not be regular later on'.

According to a previous study by the research team, ${ }^{2}$ up to seven out of ten patients are successfully treated at the fear clinic, so that patients can be treated in primary health care successfully and a new referral to the fear clinic is not needed.

Dr Kankaala said that the fear of dental treatment should be discussed, especially if the patient cancels appointments, does not come to dental care at all or repeatedly seeks emergency treatment for pain: 'Fearful patients can be challenging, and health care workers. If the situation is not addressed, contrary to common belief, the child's severe fear of dental care will usually not ease as the child grows. Appropriate, individually designed treatment of dental fear benefits not only the patient but also the medical staff, as well as reducing the costs of treatment for all parties in the long term'.

\section{References}

1. Kankaala T, Laine H, Laitala M L et al. 10-year follow-up study on attendance pattern after dental treatment in primary oral health care clinic for fearful patients. BMC Oral Health 2021; doi: 10.1186/s12903-021-01869-6.

2. Kankaala T, Määttä T, Tolvanen M, Lahti S, Anttonen V. Outcome of chairside dental fear treatment: long-term follow-up in public health setting. Int $J$ Dent 2019; doi: 10.1155/2019/5825067. their treatment can be burdensome for oral

\section{DENTAL HYGIENIST MHARI IS NEW PRESIDENT OF THE ORAL HEALTH FOUNDATION}

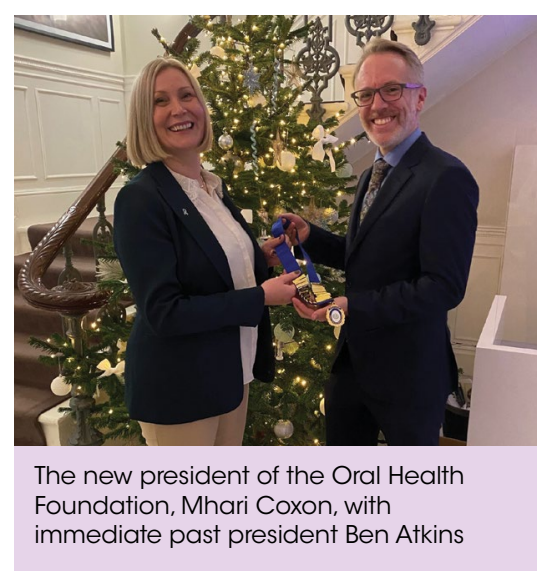

Mhari Coxon has been appointed as the new president of the Oral Health Foundation.

Mhari is a registered dental hygienist whose career portfolio has spanned general practice, hospital environments, working for dental associations and faculties, and healthcare marketing. She is currently Healthcare and Prescription Marketing Strategy Lead for Northern Europe at Johnson \& Johnson and is a member at the Chartered Institute of Marketing and a fellow of the Chartered Management Institute.

Mhari said: 'As an organisation we're regarded as one of the leading voices on oral health in the UK. During my presidency, I hope to shape and build upon this and use our position to help influence how the public view their oral health, how they connect it to their overall health, and empower them to get familiar with their oral health, encouraging early detection of disease and pushing the power of prevention'.

Mhari is the charity's $13^{\text {th }}$ president, succeeding Manchester-based dentist Ben Atkins, who remains on the board of trustees.

Mhari acknowledged the work carried out by Ben in leading the board over the last two years and said: 'Being president of the charity throughout the pandemic is not a small task and the work which [Ben] has done during this time leading the Oral Health Foundation is exceptionally admirable'. 